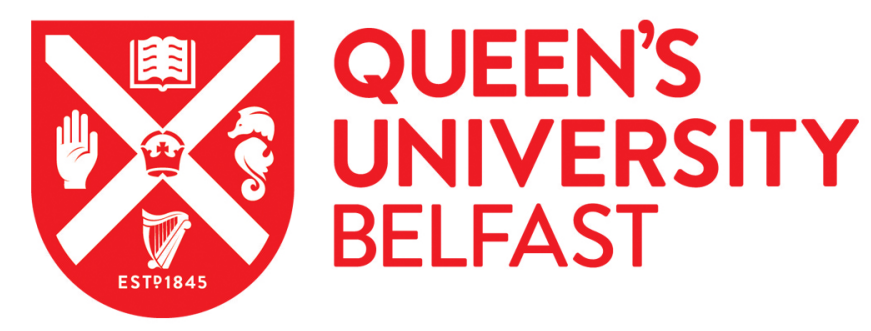

\title{
IIIness perception clusters at diagnosis predict psychological distress among women with breast cancer at 6 months post-diagnosis.
}

\author{
McCorry, N., Dempster, M., Quinn, J., Hogg, A., Newell, J., Moore, M., Kelly, S., \& Kirk, S. (2013). Illness \\ perception clusters at diagnosis predict psychological distress among women with breast cancer at 6 months \\ post-diagnosis. Psycho-oncology, 22(3), 692-698. https://doi.org/10.1002/pon.3054
}

Published in:

Psycho-oncology

Document Version:

Peer reviewed version

Queen's University Belfast - Research Portal:

Link to publication record in Queen's University Belfast Research Portal

\footnotetext{
General rights

Copyright for the publications made accessible via the Queen's University Belfast Research Portal is retained by the author(s) and / or other copyright owners and it is a condition of accessing these publications that users recognise and abide by the legal requirements associated with these rights.
}

Take down policy

The Research Portal is Queen's institutional repository that provides access to Queen's research output. Every effort has been made to ensure that content in the Research Portal does not infringe any person's rights, or applicable UK laws. If you discover content in the Research Portal that you believe breaches copyright or violates any law, please contact openaccess@qub.ac.uk. 
Running head: ILLNESS PERCEPTIONS AND PSYCHOLOGICAL DISTRESS

Illness perception clusters at diagnosis predict psychological distress among women with breast cancer at 6 months post-diagnosis

Noleen K. McCorry ${ }^{1}$, Martin Dempster ${ }^{2}$, Joanne Quinn², Alex Hogg ${ }^{2}$, Janet Newell ${ }^{3}$, Margaret Moore ${ }^{3}$, Sheila Kelly ${ }^{3}$ and Stephen J. Kirk ${ }^{3}$

${ }^{1}$ Marie Curie Cancer Care, Marie Curie Hospice Belfast, N. Ireland ${ }^{2}$ School of Psychology, Queen's University Belfast, N. Ireland

${ }^{3}$ Ulster Hospital, Dundonald, South Eastern Health \& Social Care Trust, N. Ireland

Corresponding author:

Dr Martin Dempster

School of Psychology

Queen's University Belfast

Belfast BT7 1NN

N. Ireland

Tel: +442890975547

Email: m.dempster@qub.ac.uk

Acknowledgements:

This work was supported by a pilot grant from Campaign for Breast Cancer UK. 


\begin{abstract}
Objective: This study aimed to examine the extent to which illness perceptions and coping strategies among women diagnosed with breast cancer explain psychological distress at diagnosis and at six months post-diagnosis relative to demographic and illness-related variables.

Methods: Women were recruited to the study shortly after diagnosis. A total of 90 women completed study materials (Illness Perception Questionnaire-Revised, the Cancer Coping Questionnaire and the Hospital Anxiety and Depression Scale) at time 1. The same questionnaires were sent approximately six months later to those who had consented at time 1, and completed questionnaires were returned by 72 women.

Results: Cluster analysis was used to identify groups of respondents who reported a similar profile of illness perception scores. Regression analysis demonstrated that one of these clusters was more likely to experience psychological distress than the other both at diagnosis and at six months post-diagnosis. Illness perceptions cluster membership and positive focus type coping were the most important and consistent predictors of lower psychological distress at diagnosis and at six months postdiagnosis. Conclusions: Illness perceptions remained relatively stable over the study period, and therefore we are unable to clarify whether changes in illness cognitions are associated with a corresponding change in psychological symptoms. Future research should evaluate the impact on psychological distress of interventions specifically designed to modify illness cognitions among women with breast cancer.
\end{abstract}

Keywords:

Cancer; oncology; breast cancer; depression; anxiety; illness perceptions 


\section{Introduction}

There is a growing interest in the role of cognitive factors in the experience of distress [1] among people with cancer. Previous research suggests that a useful model in helping to clarify the interrelationships between cognitive factors and various health outcomes is Leventhal's Self-Regulatory Model (SRM) [2]. The SRM proposes that in order to make sense of and cope with their illness, individuals construct internal representations of their illness, which have both cognitive and emotional content. These representations relate to thoughts about, for example, the causes, consequences and timeline of the illness, the ability to control the illness and worries and fears about the illness. These representations lead to the generation of coping responses. The individual will then assess whether their chosen coping strategies have been effective (known as the appraisal process) and this may result in the modification of the representations or coping strategies adopted $[3,4]$. There is a growing body of research evidencing strong relationships between illness cognitions and health outcomes, both physical and psychological [5-10].

Previous research in the area of oncology has already demonstrated strong relationships between illness cognitions and psychological distress. For example, even after controlling for disease related variables, illness cognitions were shown to explain a significant proportion of the variance in psychological distress in breast cancer $[6,9]$, head and neck cancer $[7,8]$ and localized prostate cancer [10]. Much of the research in this area to date has been cross-sectional, and hence the utility of illness cognitions in predicting longitudinal psychological outcomes is still unclear due to the limited number of studies utilising a longitudinal design and also a lack of consistency among findings across these studies $[6,8,11]$. This lack of consistency may exist because the nature of the longitudinal relationship between illness cognitions and health outcomes is population-specific. Therefore, caution needs to be exercised when extrapolating findings from other populations to breast cancer. The previous longitudinal research conducted among women with breast cancer did not obtain an assessment of illness perceptions and distress prior to surgical treatment and they used the Illness Perceptions Questionnaire, which has now been modified and improved[6]. Accordingly, our knowledge about the changes in illness perceptions and psychological distress among women with breast cancer, from the point of diagnosis onwards is limited.

A central tenet of the SRM is that the relationship between illness cognitions and psychological health outcomes are mediated by an individual's coping responses. There is, however, a lack of evidence to support this hypothesis $[9,12,13]$. One potential explanation for the weak relation between coping and perceived psychological health outcomes may be due to the use of generic measures of coping in previous studies [9] as they do not measure specific coping behaviours, but more generalized coping styles. Hence, research using more robust domain-specific assessments of coping is needed to better clarify the role of coping and its potential mediation between illness representations and psychological outcomes.

The evidence of relationships between illness cognitions and psychological distress demonstrated in previous research is promising, and points the way for the development of a psychological intervention for women diagnosed with breast cancer which is based on the modification of these cognitions. However, prior to the development of such an intervention it is important that we clarify the longitudinal relationships between illness cognitions, coping and psychological distress among 
women with breast cancer, and the types of cognitions that are associated with higher levels of distress within this population.

The current study seeks to clarify the relationship between illness perceptions, coping and psychological distress (anxiety and depression) at diagnosis among women diagnosed with breast cancer using a domain-specific assessment of coping, and to investigate whether illness perceptions and coping at diagnosis predicts psychological distress (anxiety and depression) at 6 months post-diagnosis.

\section{Method}

Participants were recruited from a hospital breast care clinic, approximately one to two weeks following a diagnosis of breast cancer. Women who were over the age of 18 years with a new diagnosis of breast cancer were invited to participate. Women were excluded from participation if they were identified from their notes as having a previous cancer. Those women who returned a completed consent form and study questionnaires at diagnosis were then sent further study questionnaires at six months post-diagnosis.

Participants were asked to complete a questionnaire booklet containing items relating to demographic information (age, living arrangements, number of dependents and whether they had previously accessed psychological support services) and the following questionnaires:

Illness Perception Questionnaire - Revised (IPQ-R) [14]. This questionnaire was used to assess the following illness cognitions: identity, timeline acute/chronic, timeline cyclical, personal control, treatment control, consequences, cause and illness coherence. Higher scores on the identity scale indicate that that the person associates a greater number of symptoms with the cancer. Higher scores on the personal control and treatment control scales indicate that the person has a stronger belief in the effectiveness of their ability or the treatment to control the symptoms of cancer. Higher scores on the consequences scale suggests that the person perceives more severe consequences of cancer. Higher scores on the illness coherence scale indicate that the person has a clearer understanding of the condition. Higher scores on the timeline acute/chronic and timeline cyclical scales indicate a stronger belief that the condition is chronic (rather than acute) and goes through cycles of getting better and worse rather than remaining stable.

The factor structure of the IPQ-R has been confirmed in previous research in a range of conditions, including cancer populations [15]. This previous research has not examined the factor structure of the 18 items which measure perceptions of cause of illness, as the authors of the IPQ-R suggest that the cause items should be factor analysed for each sample. Therefore, in the present research the 18 cause items were factor analysed and were found to load on three factors, which were labelled emotional causes (e.g. stress or worry), behavioural causes (e.g. smoking or alcohol use) and externalised causes (e.g. hereditary or a virus). Higher scores on the cause subscales indicate a stronger belief that this was a cause of the breast cancer. The above factor solution is consistent with previous research $[9,16]$, which also found a three factor solution. The IPQ-R has sound psychometric properties, with evidence for construct, discriminant and predictive validity and for internal and test-retest reliability [14].

The Cancer Coping Questionnaire (CCQ) [17]. The CCQ is a brief, 21 item self-rating scale designed to assess coping strategies across the following five dimensions: reflection/relaxation coping; positive focus; diversion; planning; and use of interpersonal support. Higher scores on each scale indicate that this coping strategy 
is used more often. The CCQ is therefore an example of a domain-specific coping measure, and has been found to have good reliability and validity [17].

The Hospital Anxiety and Depression Scale (HADS) [18]. This is a 14 item scale which is divided into two dimensions - anxiety and depression. Higher scores represent higher levels of anxiety and depression. Scores for the anxiety dimension and the depression dimension can be categorised as follows: 0-7: normal, 8-10: mild, 1114: moderate, 15-21: severe, with scores of eight or more indicating potentially problematic levels of distress [19]. The HADS has been validated among a population of people with cancer [20] and is the most frequently used screening tool for psychological distress in cancer care [21].

Participant's clinical and treatment related details (tumour grade, nodal status, surgery, and treatment received) were later retrieved from medical notes. The research was approved by the local Research Ethics Committee.

\section{Statistical Analysis}

To address the study aim, four hierarchical regression analyses were conducted - one for each outcome (anxiety and depression) at each point in time. Medical and demographic variables were entered into the regression models in block one; illness perception clusters (from time 1) were entered in block two; and the coping variables (from time 1) were entered in block three. In this way, we were able to determine the additional contribution to the explanation of variance in the outcome variable made by each block of variables. Additionally, this strategy allowed us to examine whether the addition of the coping variables changed the regression coefficients of the illness perception variables. If so, this would suggest that coping variables could be playing a mediating role in the model and would highlight the need for further analyses to explore this potential mediation.

Prior to being entered into the regression analyses, the illness perceptions scores at time 1 were subjected to cluster analysis. Cluster analysis is a statistical method for identifying people who have a similar pattern of scores across a series of variables. Consequently, the cluster analysis in this study provided an indication of people who share a similar pattern of illness cognitions. A two stage cluster analysis was conducted. Initially, all scores were converted to Z scores and Ward's clustering method was used to identify the number of clusters. A k-means analysis was then conducted using the number of clusters and the centroids identified by Ward's method. The squared Euclidean distance was the proximity measure chosen. On the basis of the dendrogram and the agglomeration schedule, two clusters were considered to be the optimum solution.

\section{Results}

A total of $90 / 172$ women were recruited to the study (52.3\% recruitment rate) and returned completed questionnaires at time 1. Questionnaire responses at time 2 (6 months post-diagnosis) were returned by 75 women (16.67\% attrition rate). Summary statistics for demographic and clinical characteristics are presented in Table 1.

- Table 1 here -

Analysis (t-tests and chi-square analysis) revealed no significant differences between those participants who provided data at time point 2 and those who did not on any of the demographic or clinical variables presented in Table 1, or on the illness perception, anxiety and depression scores. 
Table 2 provides the centroids for the two clusters in the cluster analysis for illness cognition variables. The centroids suggest that respondents in cluster 1 have less positive cognitions about their cancer. Specifically they have cognitions that the illness has a more chronic and cyclical timeline, more severe consequences, and associate more symptoms with the illness than respondents in cluster 2. Respondents in cluster 1 have perceptions of both lower personal and treatment control, and a less coherent understanding of the illness. They also endorse causal attributions more strongly than respondents in cluster 2 , having greater perceptions of emotional, behavioural, and externalised causes.

- $\quad$ Table 2 here -

Descriptive statistics for the two time points and the results of paired t-tests to examine the change over time on all IPQ-R and HADS subscales are presented in Table 3. Most of the illness perception variables remained stable across time, and any that changed significantly had a small effect size.

A significant improvement across time was found for anxiety scores. There was no significant change in depression scores.

- $\quad$ Table 3 here -

To examine the relationship between illness cognitions, coping, and psychological distress at diagnosis, and at six months post diagnosis we conducted a series of hierarchical regression analyses for each outcome variable (anxiety and depression) at each time point, with demographic and clinical variables, illness perceptions cluster membership, and coping scores entered as separate blocks. The regression models specified in Table 4 explained $39.2 \%$ of the variance in symptoms of anxiety $(\mathrm{F}(16,63)=4.185, \mathrm{p}<.001)$ at diagnosis, and $25.2 \%$ of the variance in symptoms of anxiety $(\mathrm{F}(16,49)=2.367, \mathrm{p}=.011)$ at six months postdiagnosis. The clinical and demographic variables contributed less than $5 \%$ of the variance explained at diagnosis (2.5\% at six months) and the illness perceptions cluster membership contributed an additional $24.6 \%$ at diagnosis (9.5\% at six months), with the coping variables contributing the remaining $10 \%$ at diagnosis $(13.2 \%$ at six months).

Women with a pattern of illness cognitions represented by cluster 2 had lower levels of anxiety at both time points than women in cluster 1 and as their use of a positive focus coping strategy increased, the reported anxiety levels at both points in time decreased. At six months post-diagnosis, anxiety levels increased in line with reports of increasing adoption of the reflection/relaxation coping strategy.

- Table 4 here -

The regression models specified in Table 5 explained $36.1 \%$ of the variance in symptoms of depression $(\mathrm{F}(16,63)=3.792, \mathrm{p}<.001)$ at diagnosis, and $17.1 \%$ of the variance in symptoms of depression $(\mathrm{F}(16,49)=1.837, \mathrm{p}=.053)$ at six months postdiagnosis. At diagnosis, the demographic and clinical variables contributed $2.6 \%$ of the variance explained (1.3\% at 6 months) and the illness perceptions cluster membership contributed an additional $20.5 \%$ (11.3\% at six months), with the coping variables contributing the remaining $13 \%$ (4.4\% at six months).

As with the anxiety outcome, women with a pattern of illness cognitions represented by cluster 2 had lower levels of depression at both time points than women in cluster 1 and as their use of a positive focus coping strategy increased, the reported depression levels at time 1 decreased. Furthermore, Table 5 indicates that women who 
had a spouse/partner showed lower levels of depression at both time points than women who did not have a spouse/partner. At six months post-diagnosis, depression levels increased in line with reports of increasing adoption of the reflection/relaxation coping strategy.

There was no evidence of a mediating role for coping in the relationship between illness perceptions and depression or anxiety at either time-point.

- $\quad$ Table 5 here -

\section{Discussion}

Overall psychological wellbeing within the sample was within the 'normal' range for depression scores and within the 'potentially problematic' range for anxiety scores (according to the HADS categorisations), with anxiety scores decreasing over time. There is, however, a subgroup of women with 'problematic' anxiety (34.7\%) and depression (15.3\%) at six months post-diagnosis. Similar results, highlighting an 'at risk' subgroup have been reported among breast cancer patients [22], and within a sample of patients with breast, prostate, and bronchial cancers [23]. Therefore, there is a need to explore methods of alleviating the psychological distress of this subgroup of women.

Our findings highlight the role that illness cognitions and coping play in the psychological distress of women with breast cancer and these are areas which might lend themselves to modification via intervention to improve psychological wellbeing, particularly for women in the 'at risk' category. More specifically, we have identified a particular pattern of illness cognitions that is associated with lower levels of psychological distress. It appears that women report lower levels of distress when they believe that their breast cancer will not last a long time and will not be cyclical in nature; when they believe that their treatment will be effective; when they do not believe that their cancer will have serious consequences for their life and when they do not have particularly strong beliefs about the cause of their breast cancer. Women who engage in a positive coping strategy also report lower levels of distress. In summary, on the basis of our findings, an intervention designed to minimise psychological distress among women with breast cancer should focus on enhancing these positive cognitions. An example of a potentially useful intervention is the positive self-talk approach [24,25].

However, it is important to note that there was little meaningful change in illness perceptions over time. This is in contrast to predictions of the SRM, and has important implications for psychological intervention in this population. Most significantly, this means that this study could provide no evidence about the effect on psychological distress among women with breast cancer, if illness perceptions changed over time. Although changes in illness perceptions across time have been noted in previous research among people with back pain [26] and osteoarthritis [27,28], previous longitudinal research conducted among people with cancer has also shown that illness perceptions remain stable over time $[6,29]$.

Our results among women with breast cancer suggest that illness perceptions within this population are resistant to change (at least within the timeframe of this study) without directed intervention aimed specifically at modifying them. Therefore, future research in this area needs to set out to purposefully change illness perceptions in order to determine whether this manufactured change will have a resultant change on levels of psychological distress. If the findings from this type of research demonstrated that psychological health outcomes changed in line with changes in 
illness perceptions, this would further strengthen the case for an illness perceptions based intervention to alleviate psychological distress among women with breast cancer.

The present study also highlights some theoretical implications. Primarily, there was no evidence that coping had a mediating role in the relationship between illness perceptions and psychological distress. These results are in contrast with the SRM but are consistent with previous research that also failed to demonstrate a mediating role for coping $[9,12,13,16]$. The current study employed a more domain specific measure of coping than the generic measures used in previous studies, and hence provides no support for the explanation offered by Rozema et al. [9] for the weak relation between coping and outcome. An alternative explanation for the failure to detect a mediating effect of coping may be the nature by which illness perceptions are assessed. Given the complexity of illness perceptions and the appraisal process suggested by the SRM, it is difficult to ascertain exactly what a participant's responses to IPQ-R items are capturing. It is possible that responses to the IPQ-R are not simply reflecting illness perceptions, but are informed by the respondent's appraisal of their ability to cope. For example, a 'disagree' response to an item such as 'The consequences of this illness are severe' may reflect an individual's appraisal of their ability to cope with severe physical, social, and economic consequences imposed by the illness via the utilization of support networks available to them.

Although the response rate in this study is considerably higher than what is usual for a postal questionnaire study, $47.7 \%$ of the women who were approached declined to participate. This limits the generalisability of the study findings, as there is no way of knowing whether there was any bias in the sample. For example, it might be the case that distress is under-estimated in the current study as women who are experiencing high levels of distress might not wish to participate in research. However, there is no way of substantiating or refuting this assumption, and the levels of psychological distress reported by women in this study are similar to that reported by women in previous research in breast cancer.

\section{Conclusions}

Previous research which has evaluated interventions designed to modify illness perceptions has shown improvements in health-related outcomes among people who have experienced a myocardial infarction [30] and among those with Type 2 diabetes [31]. However, the effectiveness of illness perceptions based interventions in the improvement of psychological distress among cancer survivors has not yet been demonstrated. Future research should evaluate the impact of interventions specifically designed to modify illness cognitions among women with breast cancer, since illness perceptions among this population appear to be fairly resistant to change (without direct intervention) over the early course of the illness experience and treatment. 


\section{References}

1. Petrie KJ, Weinman JA. Perceptions of health and illness. London: Harwood Academic Publishers. 1997.

2. Leventhal H, Meyer D, Nerenz D. The common sense model of illness danger. In Medical Psychology, Rachman S (ed.). Pergamon: New York, 1980; 7-30.

3. Nerenz DR, Leventhal H. Self-regulation theory in chronic illness. In Coping with Chronic Disease Research and Applications, Burish TG, Bradley LA (eds.). New York: Academic Press, 1983; 13-37.

4. Hale ED, Treharne GJ, Kitas GD. The Common-Sense Model of self-regulation of health and illness: how can we use it to understand and respond to our patients' needs? Rheumatology 2007; 46: 904-906.

5. Hagger MS, Orbell S. A meta-analytic review of the common sense model of illness representations. Psychol Health 2003; 18:141-184.

6. Miller K, Purushotham AD, McLatchie E, George D, Murray, GD. A 1-year prospective study of individual variation in distress and illness perceptions after treatment for breast cancer. J Psychosom Res 2005; 58: 335-342.

7. Scharloo M, Batenburg de Jong RJ, Langeveld TPM, Van Velzen-Verkaik E, Doorn-Op Den Akker MM, Kaptein AA. Quality of life and illness perceptions in patients with recently diagnosed head and neck cancer. Head Neck 2005; 27: 857-863.

8. Llewellyn, CD., McGurk, M., Weinman, J. Illness and treatment beliefs in head and neck cancer: Is Leventhal's common sense model a useful framework for determining changes in outcome over time? J Psychosom Res 2007; 63: 17-26.

9. Rozema H, Völlnick T, Lechner L. The role of illness representations in coping and health of patients treated for breast cancer. Psycho-Oncol 2009; 18, 849857.

10. Traeger L, Penedo FJ, Gonzalez JS, Dahn JR, Lechner SC, Schneiderman N, Antoni MH. Illness perceptions and emotional well-being in men treated for localized prostate cancer. J Psychosom Res 2009; 67: 389-397.

11. Llewellyn CD, Weinman J, McGurk M, Humphris G. Can we predict which head and neck cancer survivors develop fears of recurrence? J Psychosom Res 2008; 65: 525-532.

12. Heijmans M. The role of patients' illness representations in coping and functioning with Addison's Disease. Br J Health Psychol 1999; 4: 137-149. doi:10.1348/135910799168533

13. Moss-Morris R, Petrie KJ, Weinman J. Functioning in chronic fatigue syndrome: do illness perceptions play a regulatory role? Br J Health Psychol 1996; 1, 15-25.

14. Moss-Morris R, Weinman J, Petrie KJ, Horne R, Cameron LD, Buick D. The revised Illness Perception Questionnaire (IPQ-R). Psychol Health 2002; 17: 116.

15. Dempster M, McCorry NK. The factor structure of the Revised Illness Perception Questionnaire in a Population of Oesophageal Cancer Survivors. Psycho-Oncol. Early view. doi: 10.1002/pon.1927

16. Dempster M, McCorry NK, Brennan E, Donnelly M, Murray LJ, Johnston B. Psychological distress among family carers of oesophageal cancer survivors: the role of illness cognitions and coping. Psycho-Oncol 2011; 20: 698-705. doi: 10.1002/pon. 1760 
17. Moorey S, Frampton M, Greer S. The Cancer Coping Questionnaire: A selfrating scale for measuring the impact of adjuvant psychological therapy on coping behavior. Psycho-Oncol 2003; 12: 331-344.

18. Snaith RP, Zigmond AS. The Hospital Anxiety and Depression Scale. Acta Psychiatrica Scandinavia 1983; 67: 361-370.

19. Bjelland I, Dahl AA, Haug TT, Neckelmann D. The validity of the Hospital Anxiety and Depression Scale: An updated literature review. J Psychosom Res 2002; 52: 69-77.

20. Smith AB, Selby PJ, Velikova G, Stark D, Wright EP, Gould A,Cull A. Factor analysis of the Hospital Anxiety and Depression Scale from a large cancer population. Psychol Psychotherapy 2002; 75: 165-176.

21. Reuter K, Härter M. Screening for mental disorders in cancer patients discriminant validity of HADS and GHQ12 assessed by standardized clinical interview. Int J Methods Psychiatric Res 2001; 10: 86-96.

22. Henselmans I, Helgeson VS, Seltman H, deVries J, Sanderman R, Ranchor AV. Identification and prediction of distress trajectories in the first year after a breast cancer diagnosis. Health Psychol 2010; 29: 160-168.

23. Frick E, Tyroller M, Panzer M. Anxiety, depression and quality of life of cancer patients undergoing radiation therapy: a cross-sectional study in a community hospital outpatient centre. Eur J Cancer Care 2007; 16:130-6.

24. Boutin DL. Effectiveness of cognitive behavioral and supportive-expressive group therapy for women diagnosed with breast cancer: a review of the literature. J Spec Group Work 2007; 32: 267-284.

25. Zaza C, Sellick SM, Hillier LM. Coping with cancer: what do patients do? $J$ Psychosoc Oncol 2005; 3: 55-73.

26. Foster NE, Bishop A, Thomas E, Main C, Horne R, Weinman J, Hay E. Illness perceptions of low back pain patients in primary care: what are they, do they change and are they associated with outcome? Pain 2008; 136: 177-187.

27. Bijsterbosch J, Scharloo M, Visser AW, Watt I, Meulenbelt I, Huizinga TWJ, Kaptein AA, Kloppenburg M. Illness perceptions in patients with osteoarthritis: change over time and association with disability. Arthritis Rheumatism 2007; 61: 1054-1061.

28. Kaptein A, Bijsterbosch J, Scharloo M, Hampson SE, Kroon HM, Kloppenburg M. Using the common sense model of illness perceptions to examine osteoarthritis change: a 6-year longitudinal study. Health Psychol 2010; 29: 5664.

29. Dempster M, McCorry NK, Brennan E, Donnelly M, Murray LJ, Johnston B. Do changes in illness perceptions predict changes in psychological distress among oesophageal cancer survivors? J Health Psychol 2011; 16: 500-509. doi:10.1177/1359105310386633

30. Broadbent E, Ellis CJ, Thomas J, Gamble G, Petrie KJ. Further development of an illness perception intervention for myocardial infarction patients: a randomized controlled trial. J Psychosom Res 2009; 67: 17-23.

31. Skinner TC, Carey ME, Cradock S, Daly H, Davies MJ, Doherty Y, Heller S, Khunti K, Oliver L. Diabetes education and self-management for ongoing and newly diagnosed (DESMOND): process modeling of pilot study. Patient Educ Counseling 2006; 64: 369-377. 
Table 1: Participants' demographic and clinical characteristics

\begin{tabular}{|c|c|c|}
\hline \multirow{3}{*}{ Mean age (SD) } & Time 1 & Time 2 \\
\hline & $57.2(10.4)$ & $56.8(9.7)$ \\
\hline & $N(\%)$ & $N(\%)$ \\
\hline \multicolumn{3}{|l|}{ Dependents at home } \\
\hline Yes & $20(22.2)$ & $17(22.7)$ \\
\hline No & $70(77.8)$ & $58(77.3)$ \\
\hline \multicolumn{3}{|l|}{ Carer role } \\
\hline Yes & $27(30.0)$ & $24(32.0)$ \\
\hline & $62(68.9)$ & $61(68.0)$ \\
\hline Missing & $1(1.1)$ & \\
\hline \multicolumn{3}{|l|}{ Living arrangements } \\
\hline Single & $10(11.1)$ & $8(10.7)$ \\
\hline Married / Cohabitating & $64(71.1)$ & $55(73.3)$ \\
\hline Widowed / Divorced & $16(17.8)$ & $12(16.0)$ \\
\hline \multicolumn{3}{|l|}{ Previous psychological services } \\
\hline Yes & $22(24.4)$ & $18(24.0)$ \\
\hline & $67(74.4)$ & $56(74.7)$ \\
\hline Missing & $1(1.1)$ & $1(1.3)$ \\
\hline \multicolumn{3}{|l|}{ Grade of tumour } \\
\hline Grade 0 & $7(7.8)$ & $5(6.7)$ \\
\hline Grade 1 & $14(15.6)$ & $11(14.7)$ \\
\hline Grade 2 & $33(36.7)$ & $29(38.7)$ \\
\hline Grade 3 & $35(38.9)$ & $29(38.7)$ \\
\hline Unknown & $1(1.1)$ & $1(1.3)$ \\
\hline \multicolumn{3}{|l|}{ Nodal status } \\
\hline Positive & $26(28.9)$ & $23(30.7)$ \\
\hline Negative & $64(71.1)$ & $52(69.3)$ \\
\hline \multicolumn{3}{|l|}{ Treatment } \\
\hline Chemotherapy & $47(52.2)$ & $40(53.3)$ \\
\hline No chemotherapy & $41(45.6)$ & $34(45.3)$ \\
\hline Missing & $2(2.2)$ & $1(1.3)$ \\
\hline \multicolumn{3}{|l|}{ Surgery } \\
\hline Partial mastectomy & $57(56.7)$ & $44(58.7)$ \\
\hline Full mastectomy* & $38(42.2)$ & $30(40.0)$ \\
\hline Missing & $1(1.1)$ & $1(1.3)$ \\
\hline
\end{tabular}

* with or without reconstruction 
Table 2: Cluster Centroids for Illness Perceptions Clusters

\begin{tabular}{lccc}
\hline & Scale midpoint & $\begin{array}{c}\text { Cluster } \mathbf{1}(\boldsymbol{n}=55) \\
\text { Mean }(\boldsymbol{S D})\end{array}$ & $\begin{array}{c}\text { Cluster } \mathbf{2}(\mathbf{n}=\mathbf{3 2}) \\
\text { Mean }(\boldsymbol{S D})\end{array}$ \\
IPQ Acute/chronic timeline & 18 & $17.52(3.65)$ & $12.63(3.75)$ \\
IPQ Cyclical timeline & 14 & $12.78(2.26)$ & $9.69(2.83)$ \\
IPQ Treatment control & 15 & $19.25(1.90)$ & $21.88(2.27)$ \\
IPQ Emotional cause & 15 & $16.83(4.01)$ & $10.22(4.20)$ \\
IPQ Behavioural cause & 12 & $11.61(2.90)$ & $7.67(2.49)$ \\
IPQ Externalised cause & 12 & $16.76(3.07)$ & $11.93(4.74)$ \\
IPQ Consequences & 18 & $21.71(3.48)$ & $16.28(3.21)$ \\
IPQ Personal control & 18 & $19.55(3.48)$ & $21.06(4.44)$ \\
IPQ Illness coherence & 15 & $17.04(3.75)$ & $18.87(4.30)$ \\
IPQ Identity & 7.5 & $4.33(3.09)$ & $1.78(2.42)$ \\
\hline
\end{tabular}


Table 3: Change over time in IPQ and HADS subscale scores

\begin{tabular}{|c|c|c|c|c|c|c|}
\hline & $\begin{array}{l}\text { Potential } \\
\text { Midpoint }\end{array}$ & $\begin{array}{c}\text { Time } 1 \\
\text { Mean } \\
(S D)\end{array}$ & $\begin{array}{c}\text { Time } 2 \\
\text { Mean } \\
(S D)\end{array}$ & $t$ & $p$ & $\begin{array}{c}\text { Effect } \\
\text { size* }\end{array}$ \\
\hline HADS Anxiety & 10.5 & $\begin{array}{c}8.67 \\
(4.84)\end{array}$ & $\begin{array}{c}5.99 \\
(4.44)\end{array}$ & 5.753 & $<.001$ & 0.68 \\
\hline HADS Depression & 10.5 & $\begin{array}{c}4.01 \\
(4.21)\end{array}$ & $\begin{array}{c}3.99 \\
(3.59)\end{array}$ & .059 & .953 & 0.01 \\
\hline IPQ Acute/chronic timeline & 18 & $\begin{array}{l}15.75 \\
(4.47)\end{array}$ & $\begin{array}{l}15.43 \\
(5.00)\end{array}$ & .566 & .573 & 0.07 \\
\hline IPQ Cyclical timeline & 14 & $\begin{array}{l}11.42 \\
(2.94)\end{array}$ & $\begin{array}{l}10.96 \\
(3.05)\end{array}$ & 1.167 & .247 & 0.14 \\
\hline IPQ Treatment control & 15 & $\begin{array}{l}20.41 \\
(2.47)\end{array}$ & $\begin{array}{l}19.59 \\
(2.62)\end{array}$ & 2.404 & .019 & 0.29 \\
\hline IPQ Emotional cause & 15 & $\begin{array}{l}14.40 \\
(5.21)\end{array}$ & $\begin{array}{l}14.92 \\
(5.41)\end{array}$ & 1.036 & .304 & 0.12 \\
\hline IPQ Behavioural cause & 12 & $\begin{array}{l}10.05 \\
(3.32)\end{array}$ & $\begin{array}{l}11.28 \\
(3.73)\end{array}$ & 3.204 & .002 & 0.38 \\
\hline IPQ Externalised cause & 12 & $\begin{array}{l}14.73 \\
(4.20)\end{array}$ & $\begin{array}{l}15.72 \\
(3.79)\end{array}$ & 2.204 & .031 & 0.26 \\
\hline IPQ Consequences & 18 & $\begin{array}{l}19.81 \\
(4.16)\end{array}$ & $\begin{array}{l}19.81 \\
(4.49)\end{array}$ & 0.033 & .973 & 0.003 \\
\hline IPQ Personal control & 18 & $\begin{array}{l}20.10 \\
(4.13)\end{array}$ & $\begin{array}{l}19.08 \\
(4.09)\end{array}$ & 1.887 & .063 & 0.22 \\
\hline IPQ Illness coherence & 15 & $\begin{array}{l}17.83 \\
(4.03)\end{array}$ & $\begin{array}{l}18.17 \\
(3.40)\end{array}$ & 0.761 & .449 & 0.09 \\
\hline IPQ Identity & 7.5 & $\begin{array}{c}3.32 \\
(3.07)\end{array}$ & $\begin{array}{c}4.12 \\
(3.57)\end{array}$ & 2.077 & .042 & 0.25 \\
\hline
\end{tabular}

$*$ Effect size $=$ mean difference divided by SD of difference scores 
Table 4: Regression analyses with symptoms of anxiety at diagnosis and 6 months post-diagnosis as the outcome variables

\begin{tabular}{|c|c|c|c|c|c|c|c|c|}
\hline & \multicolumn{4}{|c|}{ At diagnosis } & \multicolumn{4}{|c|}{6 months post-diagnosis } \\
\hline & $b^{*}$ & Beta* $^{*}$ & $t$ & $p$ & $b^{*}$ & Beta* & $t$ & $p$ \\
\hline Block 1 & & & & & & & & \\
\hline $\begin{array}{l}\text { Treatment } \\
(0=\text { no chemo; } 1=\text { chemo })\end{array}$ & .524 & .052 & .341 & .734 & -.501 & -.055 & -.304 & .762 \\
\hline $\begin{array}{l}\text { Living arrangements } \\
(0=\text { not in; } 1=\text { in relationship })\end{array}$ & -1.670 & -.147 & -1.448 & .153 & -2.593 & -.241 & -1.796 & .079 \\
\hline $\begin{array}{l}\text { Nodal status } \\
(0=\text { negative; } 1=\text { positive })\end{array}$ & -1.136 & -.104 & -.994 & .324 & .146 & .015 & .117 & .908 \\
\hline $\begin{array}{l}\text { Surgery } \\
(0=\text { partial; } 1=\text { full mastectomy })\end{array}$ & .193 & .019 & .197 & .845 & .928 & .101 & .818 & .418 \\
\hline $\begin{array}{l}\text { Dependents } \\
(0=\text { no; } 1=\text { yes })\end{array}$ & 2.397 & .196 & 1.751 & .085 & .349 & .032 & .235 & .815 \\
\hline $\begin{array}{l}\text { Carer } \\
(0=\text { no; } 1=\text { yes })\end{array}$ & .090 & .008 & .080 & .936 & .140 & .014 & .112 & .911 \\
\hline $\begin{array}{l}\text { Previous psych services } \\
(0=\text { no; } 1=y e s)\end{array}$ & .145 & .013 & .129 & .898 & 1.427 & .138 & 1.109 & .273 \\
\hline Age & -.063 & -.129 & -1.162 & .249 & .047 & .096 & .729 & .469 \\
\hline Tumour grade 3 vs 0 & 2.023 & .114 & .956 & .343 & 1.146 & .067 & .462 & .646 \\
\hline Tumour grade 3 vs 1 & 3.081 & .227 & 1.573 & .121 & 1.258 & .100 & .580 & .565 \\
\hline Tumour grade 3 vs 2 & .087 & .008 & .068 & .946 & 1.210 & .131 & .902 & .372 \\
\hline Block 2 & & & & & & & & \\
\hline $\begin{array}{l}\text { Cognitions cluster } \\
(1 \text { vs } 2)\end{array}$ & -4.345 & -.418 & -4.288 & $<.001$ & -2.323 & -.250 & -2.100 & .041 \\
\hline Block 3 & & & & & & & & \\
\hline CCQ Reflect/relaxation & .419 & .275 & 1.977 & .052 & .619 & .451 & 2.660 & .011 \\
\hline CCQ Positive focus & -.626 & -.302 & -2.549 & .013 & -.765 & -.429 & -2.870 & .006 \\
\hline CCQ Diversion & .371 & .183 & 1.400 & .166 & -.042 & -.024 & -.140 & .889 \\
\hline CCQ Planning & -.154 & -.073 & -.634 & .528 & .069 & .038 & .259 & .797 \\
\hline Constant & 17.077 & & 3.720 & $<.001$ & 5.530 & & 1.095 & .279 \\
\hline
\end{tabular}


Table 5: Regression analyses with symptoms of depression at diagnosis and 6 months postdiagnosis as the outcome variables

\begin{tabular}{|c|c|c|c|c|c|c|c|c|}
\hline & \multicolumn{4}{|c|}{ At diagnosis } & \multicolumn{4}{|c|}{6 months post-diagnosis } \\
\hline & $b^{*}$ & Beta* & $t$ & $p$ & $b^{*}$ & Beta* & $t$ & $p$ \\
\hline \multicolumn{9}{|l|}{ Block 1} \\
\hline $\begin{array}{l}\text { Treatment } \\
(0=\text { no chemo; } 1=\text { chemo })\end{array}$ & -.810 & -.105 & -.665 & .508 & -.041 & -.006 & -.030 & .976 \\
\hline $\begin{array}{l}\text { Living arrangements } \\
(0=\text { not in; } 1=\text { in relationship })\end{array}$ & -1.909 & -.217 & -2.088 & .041 & -2.636 & -.304 & -2.156 & .036 \\
\hline $\begin{array}{l}\text { Nodal status } \\
(0=\text { negative } ; 1=\text { positive })\end{array}$ & -1.407 & -.167 & -1.554 & .125 & .122 & .016 & .116 & .908 \\
\hline $\begin{array}{l}\text { Surgery } \\
(0=\text { partial; } 1=\text { full mastectomy })\end{array}$ & 1.181 & .150 & 1.516 & .135 & .194 & .026 & .202 & .841 \\
\hline $\begin{array}{l}\text { Dependents } \\
(0=\text { no } ; 1=\text { yes })\end{array}$ & 1.637 & .173 & 1.509 & .136 & .619 & .071 & .492 & .625 \\
\hline $\begin{array}{l}\text { Carer } \\
(0=\text { no; } 1=\text { yes })\end{array}$ & .600 & .070 & .673 & .504 & 1.116 & .141 & 1.057 & .296 \\
\hline $\begin{array}{l}\text { Previous psych services } \\
(0=\text { no; } 1=y e s)\end{array}$ & -.920 & -.103 & -1.032 & .306 & .748 & .090 & .687 & .495 \\
\hline Age & -.066 & -.173 & -1.515 & .135 & .027 & .069 & .499 & .620 \\
\hline Tumour grade 3 vs 0 & -1.318 & -.096 & -.787 & .434 & -.589 & -.043 & -.281 & .780 \\
\hline Tumour grade 3 vs 1 & 1.291 & .123 & .831 & .409 & .049 & .005 & .027 & .979 \\
\hline Tumour grade 3 vs 2 & -.205 & -.026 & -.203 & .840 & .597 & .080 & .525 & .602 \\
\hline \multicolumn{9}{|l|}{ Block 2} \\
\hline $\begin{array}{l}\text { Cognitions cluster } \\
(1 \text { vs } 2)\end{array}$ & -3.256 & -.405 & -4.056 & $<.001$ & -2.692 & -.360 & -2.874 & .006 \\
\hline \multicolumn{9}{|l|}{ Block 3} \\
\hline CCQ Reflect/relaxation & .289 & .246 & 1.723 & .090 & .501 & .454 & 2.543 & .014 \\
\hline CCQ Positive focus & -.760 & -.474 & -3.908 & $<.001$ & -.277 & -.193 & -1.229 & .225 \\
\hline CCQ Diversion & -.040 & -.026 & -.193 & .848 & -.402 & -.279 & -1.582 & .120 \\
\hline CCQ Planning & -.040 & -.026 & -.193 & .848 & .046 & .032 & .204 & .839 \\
\hline Constant & 15.565 & & 4.280 & $<.001$ & 6.642 & & 1.554 & .127 \\
\hline
\end{tabular}

$* \mathrm{~b}=$ Unstandardised regression coefficient Beta $=$ Standardised regression coefficient 